\title{
Criteria for Consultant Posts in Psychiatry
}

Unfortunately the version of 'Criteria for Consultant Posts in Psychiatry' which appeared in the August 1986 Bulletin was out of date. The version agreed in 1985 , which coincides with that included in the JCHPT Handbook 1985, and which is currently circulated to Assessors on Advisory Appointment Committees, is as follows:

1. Before appointment to a Consultant post, whether in general psychiatry or one of the other psychiatric specialties, a candidate should normally have undertaken a basic training in psychiatry and hold the MRCPsych or equivalent qualification. If there is an outstanding candidate, or circumstances are highly exceptional, other relevant qualifications and experience may constitute an acceptable alternative.

2. The successful candidate should normally have reached the age of 32, but there is no bar to the appointment of younger applicants.

3. Due weight should be attached to breadth of experience, participation in organised rotation schemes, periods spent abroad in relevant posts, and work in medical fields allied to psychiatry.

The view of the College is that the responsibilities of all Consultant posts include the function of training those in medical and related disciplines, so that some teaching experience and supervision of trainees is desirable in candidates for appointment as Consultant. Experience in research, especially if this had proved worthy of publication, will enhance a candidate's application. But even the most outstanding experience of this kind should not be allowed to over-ride the essential requirements laid down in (1) above.

4. The Joint Committee on Higher Psychiatric Training (JCHPT) has decided not to institute an accreditation procedure at this stage. Senior Registrar or equivalent posts have, however, been inspected and approved and the JCHPT urges College Assessors to ensure that candidates have been trained in such posts and that they are not normally appointed to the consultant grade before completing at least three years of higher training. For further details regarding the Joint Committee's requirements for specialist training please see JCHPT Handbook, August 1985.

5. Specific requirements for various types of Consultant posts are as follows:

\section{(a) General Psychiatry}

Normally three years of recognised general professional training in psychiatry followed normally by at least three years of higher training in an approved training post. Exceptions may occasionally be made for outstanding candidates with other relevant experience (e.g. research or service overseas) but a minimum of five years training in psychiatry, including clinical research, is still required. Although part of the period of higher training can be spent working in other specialised fields, at least two years fulltime (or part-time equivalent) must have been spent in a general adult psychiatry post educationally approved by the JCHPT specifically for the purpose of training in preparation for a consultant post in general adult psychiatry.

\section{(b) Child and Adolescent Psychiatry}

Basic training in psychiatry, which may also include time in a registrar post in child psychiatry, should have been followed by experience in all aspects of the specialty in a Senior Registrar training post, normally for a period of three years.

\section{(c) Mental Handicap Psychiatry}

Specialist training in mental handicap should be obtained at Senior Registrar level in a training scheme which can offer further experience in those aspects of mental handicap necessary to consultant psychiatric practice in this field. A candidate for a full-time specialist post in mental handicap should have held a Senior Registrar or equivalent academic post in a training scheme normally for a period of three years.

\section{(d) Forensic Psychiatry}

A candidate for a full-time specialist post in forensic psychiatry should have held a Senior Registrar or equivalent academic post in a training scheme normally for a period of three years. Evidence should be sought that a candidate has had adequate training in general psychiatry and in rehabilitation psychiatry. Experience in related fields should be given due weight.

(e) Psychotherapy

A candidate for a full-time psychotherapy specialist post should have held a Senior Registrar post in a training scheme for a minimum period of three years.

\section{(f) Psychiatry of Old Age}

Candidates should have held a Senior Registrar post in general psychiatry normally for three years including a period of at least one year but usually eighteen months full-time experience in psychiatry of old age.

(g) Consultants in General Psychiatry with a Special Interest in a Named Specialty

Posts are often advertised for consultants to work in general psychiatry with a 'special interest' in one of the following subjects-alcoholism and/or drug addiction; rehabilitation; the psychiatry of old age; liaison psychiatry; behavioural treatments; mental handicap; forensic psychiatry; physotherapy; and adolescent psychiatry. (Child and adolescent psychiatry cannot, however, be a special interest subject for a general psychiatrist). Candidates for such posts need to have had substantial experience both in general psychiatry and in the special interest subject.

Candidates for 'special responsibility' posts should have undertaken two years higher training in general psychiatry 
and not less than one year or its part-time equivalent in the area of special interest.

Candidates for joint posts should have undertaken not less than eighteen months in each of the disciplines.

\section{(h) Special Hospitals}

While most consultants in Special Hospitals will be forensic psychiatrists trained in approved posts, those trained in general psychiatry or in mental handicap with a special interest in forensic psychiatry could well contribute to the work of a Special Hospital. The consultant with a special interest in forensic psychiatry should have held an approved post for at least one year. With both, the forensic psychiatry and special interest posts training experience in a related field should be given due weight. It is important that the specialty and the special interest contribution are clearly identified before hand and that these are reflected in the job description.

\section{College Prizes, Medals and Travelling Fellowships}

\section{Gaskell Medal and Prize}

This is considered to be one of the foremost academic distinctions in psychiatry. The Prize, value $£ 500$, is awarded on the results of an annual examination, which will be held next in May/June 1987. Candidates should be qualified medical officers with a minimum of two years' service in mental hospitals or clinics in psychiatry in the United Kingdom or elsewhere in the British Commonwealth; they should be between 23 and 35 years of age and possess the MRCPsych or any other degree or diploma in psychological medicine.

Application forms are obtainable from the Education Department at the College and should be completed and returned not later than 31 March 1987, enclosing an entry fee of $£ 5.00$, which is returnable to bona fide candidates.

\section{Gillian Page Prize}

A biennial award of $£ 500$ is made for an original piece of work in the field of adolescent psychiatry, which may take the form of a research project, a review of a particular topic or a study of some clinical innovation. Applicants must be Members or Inceptors of the College below the rank of consultant (or equivalent). Applicants must submit a title and short protocol of their project for approval by the Examiners at an early stage to ensure that it falls within the scope of the award. Final entries for the Prize should be presented in the form of an essay or dissertation with accompanying tables and figures. A collection of articles will not be accepted as a submission, but previously published work may be included if incorporated in the essay or dissertation. Final entries should be submitted to the Dean of the College by 31 March 1987.

\section{Langhlin Prize}

This Prize is awarded twice a year to the candidate who obtains the highest mark and the best recommendations from the Examiners in the Membership Examination. The value of the Prize is currently $£ 250$.

\section{Research Prize and Bronze Medal}

Entry for the Research Prize (value £500) is open to
Members or Inceptors of the College below the rank of consultant psychiatrist. The research should be presented in the form of an essay or dissertation, with tables or figures (not exceeding 10,000 words), may incorporate previously published work and may involve collaboration with other workers, provided that this is clearly indicated and attributed. Entries should be sent to the Dean of the College by 31 March 1987.

\section{Squibb Travelling Fellowship}

The Fellowship, present value $£ 5,000$, is awarded for travel abroad to one or two centres, and is open to Members of the College working in the UK or the Republic of Ireland of senior registrar or lecturer grade, or consultants within the first three years of their appointment. Applications, stating nature of study abroad, with confirmation from the host centre(s), should be sent to Dean of the College by $\mathbf{3 0}$ April 1987. (Full details of the Fellowship will appear in the Bulletin, January 1987).

\section{Woodford Williams Prize}

The Prize, value $£ 300$, is offered every three years commencing in 1988 for research under the broad heading of prevention of dementia (including primary, secondary and tertiary prevention). Applicants must be Members of, or Associates with, the College. Research involving collaboration between workers may be submitted, and the submission should indicate which parts were undertaken by each worker, and should include a statement to this effect signed by all collaborating workers. A summary (200-500 words) of the proposed submission should be submitted to the Dean by 31 March 1987. Final submissions, in the form of an essay or dissertation (between 10,000 and 30,000 words, including figures and tables), together with a curriculum vitae and list of relevant publications, must be submitted to the Dean by 31 March 1988. (Full details of the Prize appeared in the Bulletin, September 1986, 10,9.)

Further details of all Prizes and Fellowships are obtainable from the Education Department at the College. 